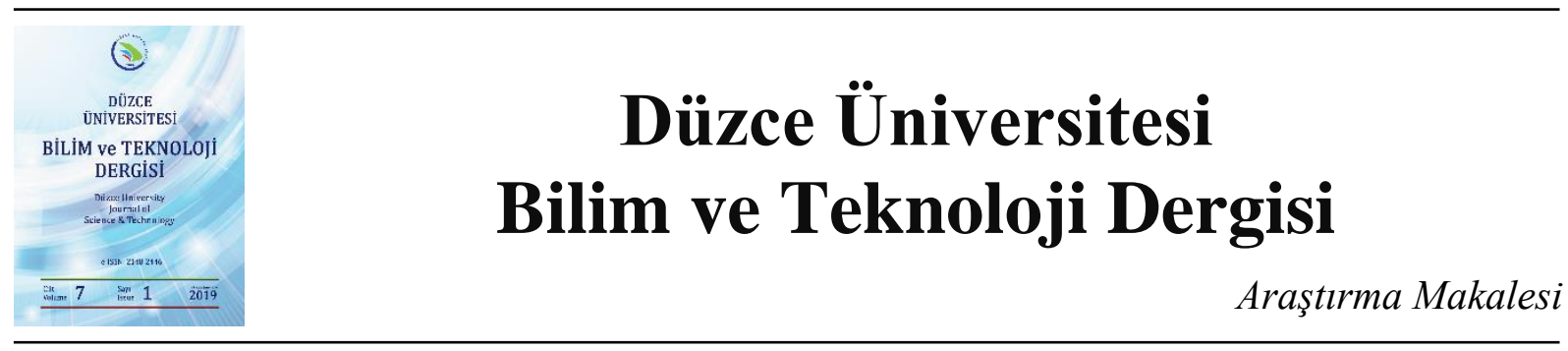

\section{Nesnelerin İnterneti ile Akıllı bir Priz Prototipi}

\author{
Mustafa DENIZLİ a , Mustafa AYYILDIZ ${ }^{\text {b,* }}$ \\ ${ }^{a}$ Fen Bilimleri Enstitüsü, Düzce Üniversitesi, Düzce, TÜRKIYE \\ ${ }^{b}$ Makine ve İmalat Mühendisliği Bölümü, Teknoloji Fakültesi, Düzce Üniversitesi, Düzce, TÜRKIYYE \\ * Sorumlu yazarin e-posta adresi: mayyldz@hotmail.com
}

\begin{abstract}
ÖZET
Teknolojinin hızla gelişmesiyle birlikte cihazların uzaktan kontrol ihtiyacı hızla artmıştır. Cihazların bir ağ üzerinden uzaktan etkileşebilir hale getirilmesi nesnelerin interneti sayesinde mümkündür. $\mathrm{Bu}$ çalışmada üzerinde ESP8266 wifi modül barındıran Nodemcu V3 geliştirme kartı tercih edilerek cihazların uzaktan kontrolü sağlanmıştır. Burada NodemCU V3, android yazılım tabanlı uzaktan yönetim uygulaması ve bir prizden oluşan akıllı bir sistemin entegrasyonu sağlanmıştır. ESP8266 modülü ile yönetilmek istenen cihazlar kontrol edilebilmektedir. Kullanılan sensörler ESP8266 aracilığıyla anlık olarak veri iletmektedir. İnsanların çoğu günlük yaşamlarını evleri dışında geçirdiği için ev ortamında karşılaşabileceği gaz kaçağı, cihazların prizde unutulması, ışıkların açık bırakılması vb. olumsuz durumlarda ister internet tarayıcısı üzerinden isterse mobil uygulama üzerinden prizlerin uzaktan kontrolünü sağlayabileceklerdir. Bu şekilde daha güvenli ve ekonomik bir yaşam imkânı sağlanmış olacaktır.
\end{abstract}

Anahtar Kelimeler: NodemCU V3, Sensör, Akıllı priz, Android

\section{Smart a Socket Prototype with Internet of Things}

\begin{abstract}
With the rapid development of technology, the need for remote control of devices has increased rapidly. Remotely interacting devices over a network is possible through the Internet of Things. In this work, remote control of the devices is provided by using the NodemCU V3 development card. The integration of NodemCU $\mathrm{V} 3$, Android software based remote management application and an intelligent system consisting of a socket is provided. With the ESP8266 module, devices that need to be managed can be controlled. The sensors used, transmits data instantaneously through ESP8266. Since most people spend their daily lives outside their homes, they will be able to remotely control the power outlets through both the Internet browser and the mobile application, in cases of gas leakages, plugged in devices, open lights, etc. In this way, a safer and more economical life will be provided.
\end{abstract}

Keywords: NodemCU V3, Smart socket, Android 


\section{GiRISS}

$\mathrm{N}^{2}$ esnelerin İnterneti cihazların birbiri ile haberleşmelerini sağlamaktadır. Akıllı sistemler, insanların hayatını rahatlatmak, ekonomik açıdan fayda sağlamak, enerji tasarrufu sağlama ve insan hayatı güvenliğinin sağlanması amacıyla geliştirilmektedir. Gaz kaçağı tespitleri, açılıp kapanan kapılar, üretimde kullanılan robotlar gibi teknolojik ürünler bu alanda yapılan uygulamalar olarak gösterilebilir [1]. Literatürdeki çalışmalara bakıldığında akıllı ev sistemi sensörler yardımıyla elektrik, su gibi tüketimlerini kontrol eden bir sistem uygulanmıştır [2]. İnal ve arkadaşları yaptıkları çalışmada cep telefonu ile kişilerin evlerini uzaktan kontrol etme imkânı sağlamışlardır [3]. Akıllı sistemler ile ilgili biyomedikal alanında da birçok çalışma yapılmıştır. Faruk ve arkadaşları yapmış olduğu çalışmada hastane ortamında veya hastane dışı ortamlardan fizyolojik verilerin izlenilebileceği ön görülmüştür [4]. Hüseyin ve arkadaşları ortaya koymuş olduğu çalışmada kişilerin kullandığı cihazların günün belirli saatlerinde kullanımlarını kayıt altına alabilecek bir yazılım geliştirmişlerdir [5]. Kubik ve Sugisaka yaptıkları çalışma ile mobil uygulama üzerinden ses ile robot kontrolünü sağlamışlardır [6]. Astarita ve ark. mobil uygulama üzerinden trafik yönetimi sağlanması için nesnelerin internetine başvurmuştur [7]. İbrahim ve Salih yapmış oldukları çalışmada telefon tuş takımı üzerinden verilen komutlar yardımıyla sulama sistemlerinin uzaktan kontrolünü sağlamışlardır [8]. İbrahim ve Hande, Tapiex adlı programı kullanılarak evdeki cihazların açma, kapama ve süre denetimlerini sağlamışlardır [9]. Akıllı sistemlerin geliştirilmesi ve üretilmesi giderek hızlanmaktadır. Özellikle Endüstri 4.0 nesnelerin interneti uyumuyla bu alanlarda benzer akıllı sistem çalışmaları yapılmaktadır. $\mathrm{Bu}$ çalışmada Endüstri 4.0'ın bir modülü olan nesnelerin interneti teknolojisi kullanılarak örnek bir akıllı priz prototipi gerçekleştirilmiştir.

\section{ENDÜSTRI 4.0}

Üretim süreçlerinin veri merkezli bilimsel metotlar ile yönetildiği nesnelerin interneti, robotlar, siber güvenlik, bulut bilişim, sistem entegrasyonu, büyük veri, arttırılmış gerçeklik, eklemeli üretim ve simülasyon teknolojilerinin birlikte kullanılmasıyla meydana gelen yeni sanayi devrimine verilen isimdir [10].

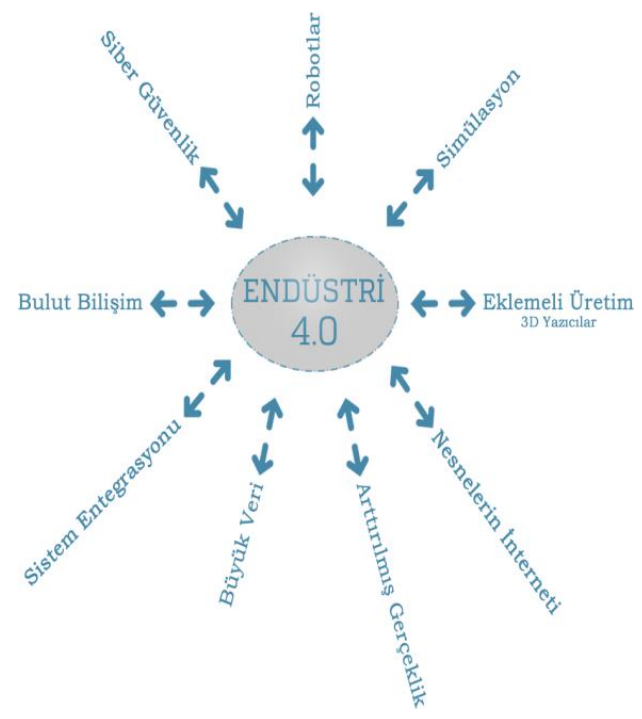

Şekil 1. Endüstri 4.0 Yapısı 
Özellikle otomotiv sanayi, havacılık, savunma ve ilaç gibi farklı sektörlerde Endüstri 4.0'a çoktan geçilmiş̧ir. Türkiye'de birçok Japon ve Alman firmaları bu sürecin içerisinde lider konumdadır. 2014 yılında 5 Amerikan şirketi, nesnelerin interneti ve makinelerin veriyi paylaşma ve taşıma biçimi için standartları belirlemeye yardımcı olmak amacıyla Endüstriyel İnternet Konsorsiyumu'nu (Industrial Internet Consortium, IIC) kurdu. AT\&T, IBM, Cisco, Intel ve General Electric'ten oluşan bu beş kurucu şirket, nesnelerin interneti endüstrisinin pazar büyüklügünün arttırılmasına ve ürün geliştirmeyi iyileştirmeye yardımcı olmak için hızla çalışmaktadırlar [11]. Ülkelerin gayrisafi milli hasılasına bakıldığında, geçmiş yıllarda Avrupa ülkelerinin, üretimi milli tutmakta zorluklar yaşamış olduğu görülmektedir. Gayrisafi milli hasıla üzerinde endüstrinin payını arttırabilen tek Batı Avrupa ülkesi Almanya olmuştur. Alman şirketlerinin \%90'dan fazlası, üretim merkezi olarak Almanya'nın önümüzdeki yıllar içinde önemini korumaya devam edeceğini düşünmektedir. $\mathrm{Bu}$, endüstrinin Almanya'daki önemini de göstermektedir. Ayrıca, birçok firma için Almanya ilgi çekici bir yer durumundadır. Özellikle Alman firması olan Siemens, dördüncü sanayi devrimine öncülük eden şirketler arasında yer almaktadır. Barselona, İspanya da nesnelerin interneti için önemli bir merkez durumundadır. Nesnelerin interneti tabanlı girişimleri arttırmak ve hızlandırmak için "Start up" destek kamp1 gerçekleştirmiştir. Amerikan şirketi Cisco da Barselona'ya 30 milyon dolarlık bir yatırım yaparak, bir girişim merkezi inşa etti. Amaç araştırma, teknolojik gelişim ve yeni market firsatları oluşturmaktır. Endüstri 4.0, Birleşik Krallık tarafından da göz ardı edilmemektedir. Birleşik Krallık'ın Bilim Bakanı David Willets, hükümetin desteklediği sekiz teknolojiden birinin Robotik ve Otonom Sistemler olduğunu belirtmiştir. Coventry yakınlarında, Siemens ve HP tarafından bir üretim merkezi kurulmuş, Birleşik Krallıktaki ilk dijital fabrika ve Endüstri 4.0 için de bir vitrin durumundadır [12]. Dünyadaki duruma bakıldığında, Endüstri 4.0'a götürecek teknolojilere yatırım yapmanın getirisinin büyük olacağı görülmektedir.

\section{MATERYAL YÖNTEM}

NodemCU V3 açık kaynak kodlu programlanabilir elektronik bir devredir. Nesnelerin interneti uygulamalarını ekonomik yollardan gerçekleştirebilmek için üretilmiştir. NodemCU V3 devresini programlamak için "lua" adı verilen programlama dili kullanılmaktadır. Lua genellikle gömülü sistemler ve istemciler için tasarlanmış C'de yazılmış bir programlama dilidir [13]. Bunun yanında Arduino IDE programiyla da programlanabilmektedir [14]. Bu devrenin tercih edilmesinin en önemli sebebi kablosuz ağlara bağlanabildiği gibi, kendi internet ağını yayarak diğer cihazların bağlantı kurmasına imkân sağlamasıdır. Bu çalışmada örnek bir akıllı priz prototipi olup NodemCU V3 kartı, gerilim dönüştürücü kartı, MQ-4 metan gazı sensörü, 5V röle bileşenlerinden oluşmaktadır. Gerilim dönüştürücü kartı, NodemCU V3 kartını beslemek için 220 voltu 5 volta düşürecek bir devredir. Ortamdaki gaz kaçağının tespit edilebilmesi için MQ-4 metan sensörü tercih edilmiştir. MQ-4 sensörü havada 300ppm ve 10000ppm seviyesindeki gazı algılamakta kullanılmaktadır [15]. Bu sensör aracılığı ile analog gerilim çıkışı alınabilmektedir. Prizin açık veya kapalı konumlarını tetiklemek amacıyla $5 \mathrm{~V}$ röle devresi sisteme entegre edilmiştir. Akıllı priz prototipine $5 \mathrm{~V}$ çıkış verebilen mobil cihazların şarj olabilmesi için USB portu eklenmiştir. Şekil 2'de tasarlanan akıllı priz devresi gösterilmektedir. 


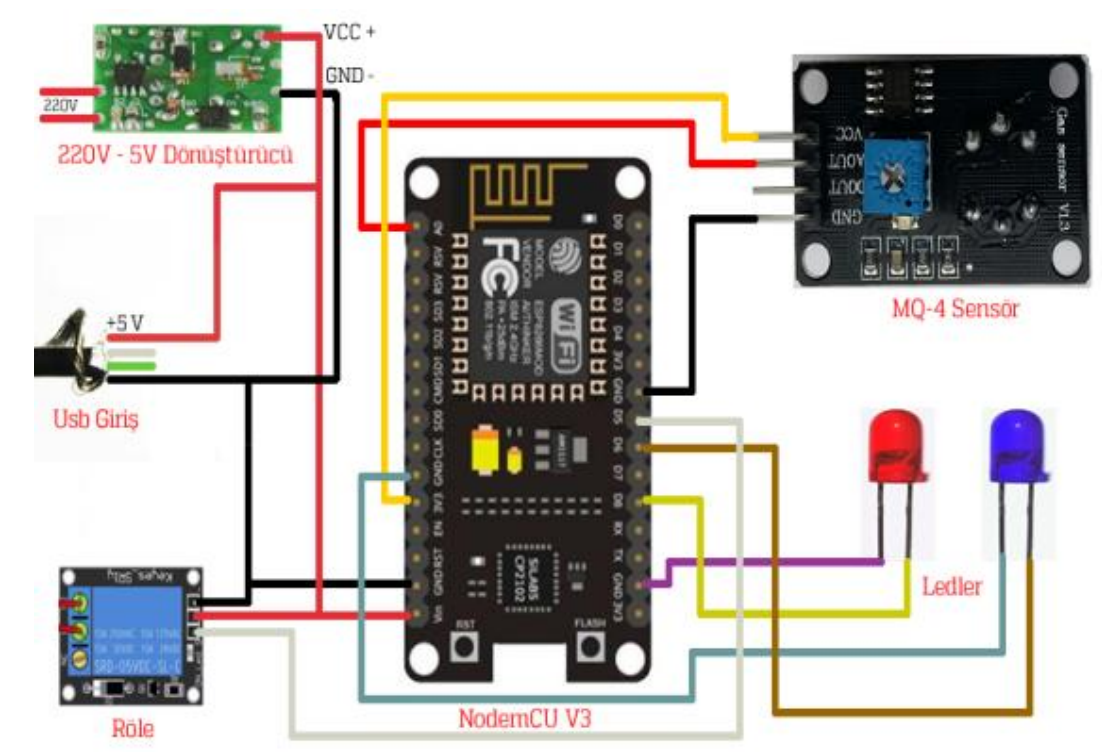

Şekil 2. Tasarlanan akillı prizin devre çizimi

Sistem hem internet tarayıcısı üzerinden hem de mobil uygulama üzerinden kontrol edilebilmektedir. Mobil uygulama android cihazlar için Android Studio adlı yazılım ile programlanıp Şekil 3a'da gösterilmiştir. Akıllı priz aktif olduğunda mavi led, pasif olduğunda ise kırmızı led yanmaktadır (Şekil $3 b)$.

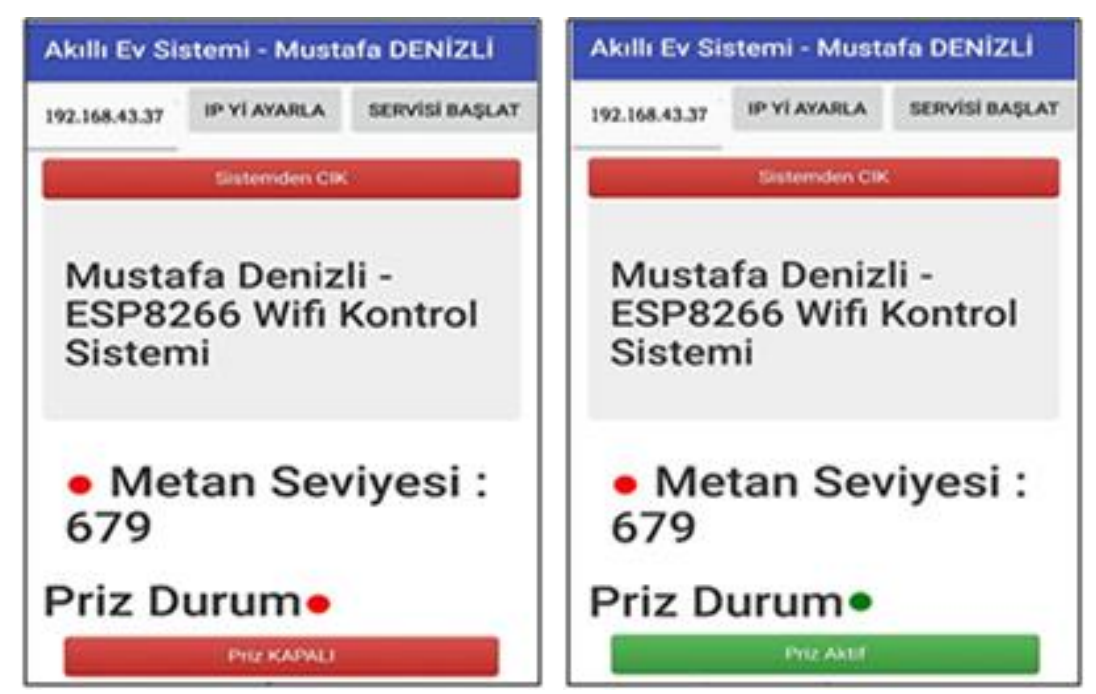

Şekil 3. (a) Prizin kapalı durumu ve (b) Prizin açık durumu

MQ-4 gaz sensörü, olası bir gaz kaçağı tespit edildiğinde devreye girmektedir. MQ-4 metan gaz sensöründen gelen veriler NodemCU V3 aracıllğ 1 ile internet ortamına atılıp gaz seviyesi verileri anlık olarak kullanıcı paneline yansıtılmakta ve anlık olarak takip edilebilmektedir. Gaz seviyesi kritik noktaya ulaştığında sistem otomatik olarak cep telefonuna uyarı bildirimi göndermektedir. Şekil 4a ve 4b'de bu uyarı gösterilmiştir. Prizin hareketleri anlık olarak kayıt altına alınıp veri olarak saklanmakta ve bir web sitesi üzerinden görüntülenebilmektedir. Şekil 5'de web sitesi üzerinde tutulan kayıtlar gösterilmiştir. 

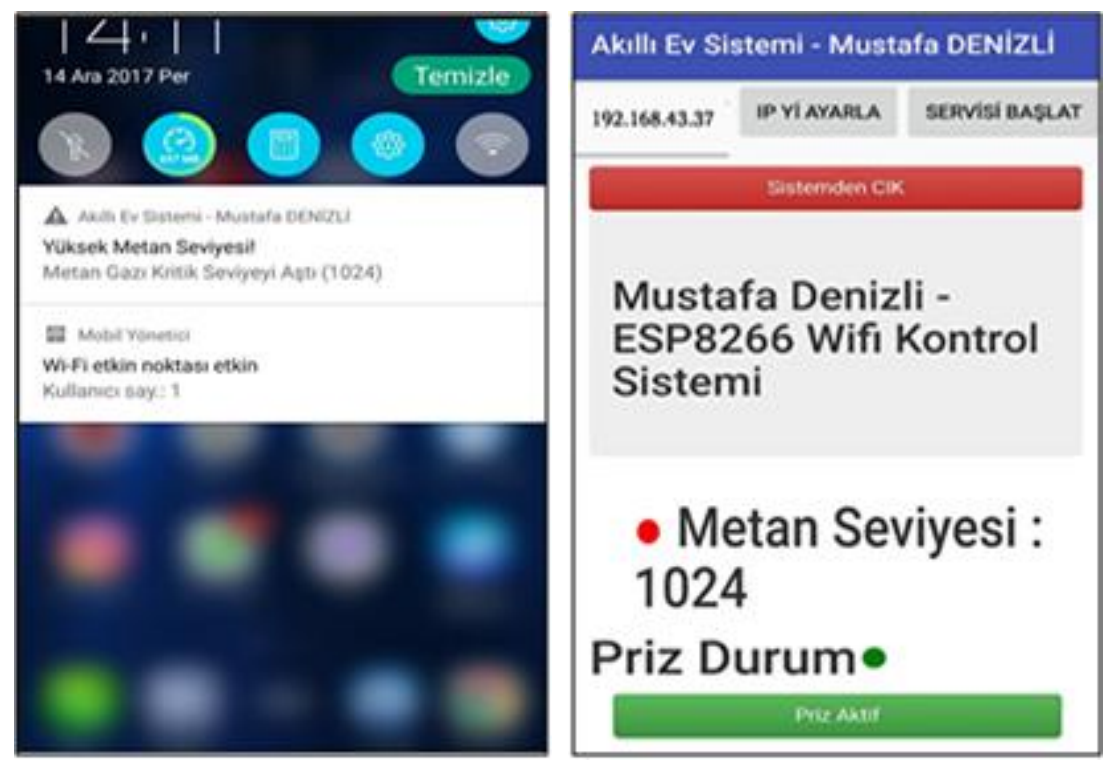

Şekil 4. (a) Mobil bildiri ve (b) Metan kritik seviye

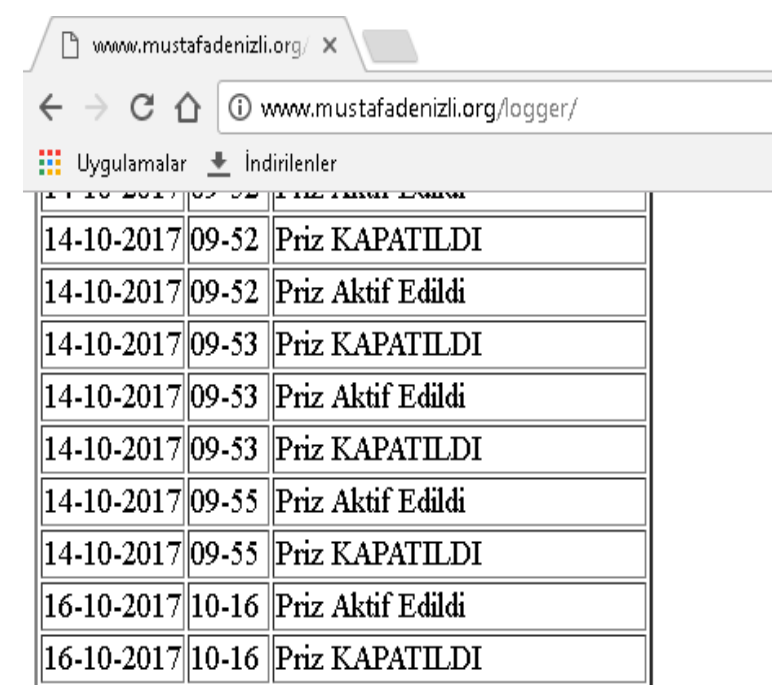

Şekil 5. Web sitesi log kayıtlart

Devre elemanlarının bir priz içinde konumlanabilmesi için yuva tasarımı gerçekleştirilmiştir. Eklemeli üretim yöntemlerinden biri olan eriyik yığma modelleme tekniği ile tasarlanan yuva 3 boyutlu yazıcıda inşa edilmiştir. Şekil 6a'da tasarlanan yuvanın prototipi, Şekil 6b'de ise tasarlanan akıllı prizin devre bağlantıları ve yuvaya montajı gösterilmektedir. 

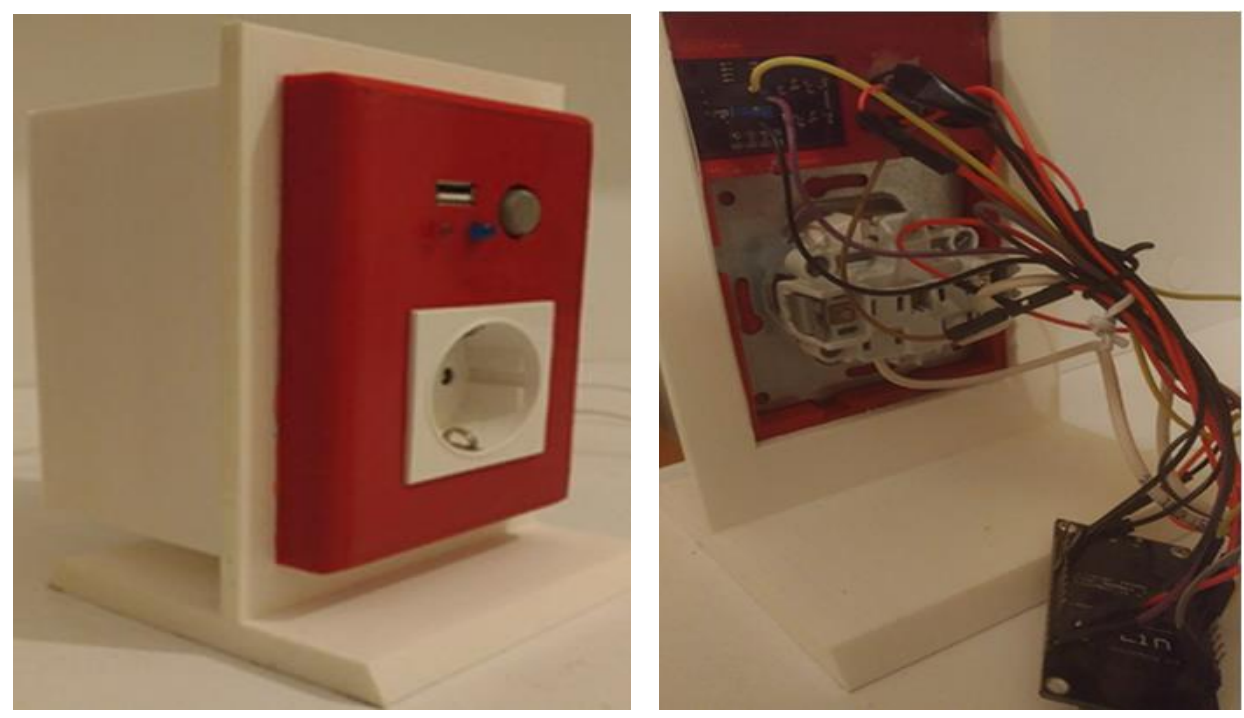

Şekil 6. (a) Tasarlanan yuvanın prototipi ve (b) Devre bă̆lantıları montajı

\section{SONUC}

Elektrikli cihazlar ve eşyaların uzaktan kontrolünü sağlamak ciddi anlamda güvenlik ve ekonomik tasarruf sağlamaktadır. Akıllı prizler insan hayatını kolaylaştıran ve güvenliğini sağlayan kontrol sistemleridir. Gerçekleştirilen bu çalışmada NodemCU V3 geliştirme kartı kullanılarak, Android uygulaması yazılarak ve 3 boyutlu yazıcıda yuva tasarımı oluşturularak örnek bir akıllı priz prototipi tasarlanmıştır. Böylece insanların ev ortamında karşılaşabileceği olumsuz durumların giderilebileceği ve ekonomik açıdan tasarruf sağlanabileceği düşünülmektedir. Gelecek çalışmada tasarlanan prototipe nem-sıcaklık sensörü ve PIR hareket sensörü eklenerek ev ortamında sıcaklık-nem bilgisinin alınması ve hareket sensörü ile de evde güvenliğinin sağlanmasında kullanılması hedeflenmektedir.

TEȘEKKÜR: Bu çalışma, Geleceğin Mühendisleri Uluslararası Öğrenci Sempozyumda (EFİS 2017) poster olarak sunulmuştur.

\section{$\underline{\text { V. KAYNAKLAR }}$}

[1] H. B, Stauffer, "Smart Enabling System for Home Automation," IEEE Transactions on Consumer electronics, vol. 37, no. 2, pp. 29-35, 1991.

[2] E. M. Tapia, S. S. Intille, and K. Larson, "Activity Recognition in The Home Using Simple and Ubiquitous Sensors," Second International Conference (PERVASIVE 2004), Linz/Vienna, Austria, 2004, pp. 158-175.

[3] K. İnal, ve M. A. Akcayol, "GSM Tabanlı Akıllı Ev Uygulaması," Bilişsim Teknolojileri Dergisi, c. 2, s. 2, ss. 37-43, 2009. 
[4] F. Aktaş, C. Çeken ve Y. E. Erdemli, "Nesnelerin İnterneti Teknolojisinin Biyomedikal Alanındaki Uygulamalar1," Düzce Üniversitesi Bilim ve Teknoloji Dergisi, c. 4, s. 1, ss. 37-54, 2016.

[5] D. Akdaş, H. Güneş, ve E. Orta, "Akıllı Ev Sistemlerinde Kullanılan Yapay Zekâ Teknikleri için Yapay Veri Üretici Geliştirilmesi," Balıkesir Üniversitesi Fen Bilimleri Enstitüsü Dergisi, c.18, s. 2, ss. 1-11, 2016.

[6] T. Kubik and M. Sugisaka, "Use of a Cellular Phone in Mobile Robot Voice Control," Proceedings of the 40th SICE Annual Conference, Nagoya, Japan, pp 106-111, 2001.

[7] V. Astarita and M. Florian, "The Use Of Mobile Phones in Traffic Management and Control," IEEE Intelligent Transportation Systems (ITSC 2001), Oakland, USA, pp. 10-15, 2001.

[8] İ. Çayıroğlu ve S. Görgünoğlu, "Mobil Telefon ve PIC Mikrodenetleyici Kullanarak Uzaktan Esnek Kontrol Sağlanmas1," International Journal of Engineering Research and Development, c. 2, s. 1, ss. 23-27, 2010.

[9] İ. Çayıroğlu ve H. Erkaymaz, "Uzaktan Sabit Hat Erişimli Bilgisayar Destekli Ev Otomasyonu," Pamukkale Üniversitesi Mühendislik Bilimleri Dergisi, c. 13, s. 3, ss. 379-385, 2007.

[10] Endüstri 4.0 ve Dijital Dönüşüm, (2017, 08 Aralık). [Online]. Erişim: http://misad.org.tr/haber_detay.php?haber_id=109.

[11] Seizing Industry 4.0 Opportunities in Japan, (2017, 12 Aralık). [Online]. Erişim: https://www.business-sweden.se/contentassets/4f2db52dbae148a78e626486d64e7c2b/seizing_industry _4_0_in_japan.pdf.

[12] Industry 4.0 - A Comparison of The Status in Europe and The USA, (2017, 12 Aral1k). [Online]. Erişim: https://static1.squarespace.com/static/559921a3e4b02c1d7480f8f4/t/585c451 d725e257dda71e3a1/1482442018860/Sabo.pdf.

[13] O. Oral ve M. Çakır, "Nesnelerin İnterneti Kavrami ve Örnek Bir Prototipin Oluşturulması," Mehmet Akif Ersoy Üniversitesi Fen Bilimleri Enstitüsü Dergisi, c. 1, ss. 172-177, 2017.

[14] K. Kayaalp ve S. Özkorucuklu, "Arduino Teknolojisi Kullanılarak Tarla İçin Radyasyon Kapı Kontrolü Tasarımı,” SDU International Journal of Technological Science, c. 7, s. 2, ss. 40-47, 2015.

[15] A. Karacı ve M. Erdemir, "Arduino ve Wifi Temelli Çok Sensörlü Robot Tasarımı ve Denetimi,” Bilişim Teknolojileri Dergisi, c. 10, s. 4, ss. 435-449, 2017. 